\title{
Factors Influencing Tourist Food Consumption *
}

\author{
Athena H.N. Mak, University of Surrey, UK \\ Margaret Lumbers, University of Surrey, UK \\ Anita Eves, University of Surrey, UK \\ Richard C.Y. Chang, Providence University, Taiwan

\begin{abstract}
* This is a draft version of the paper. For the published version, please consult the journal website: http://www.sciencedirect.com/science/journal/02784319
\end{abstract}

\begin{abstract}
This study attempts to identify the salient factors affecting tourist food consumption. By reviewing available studies in the hospitality and tourism literature and synthesising insights from food consumption and sociological research, five socio-cultural and psychological factors influencing tourist food consumption are identified: cultural/religious influences, socio-demographic factors, food-related personality traits, exposure effect/past experience, and motivational factors. The findings further suggest that the motivational factors can be categorised into five main dimensions: symbolic, obligatory, contrast, extension, and pleasure. Given the lack of research in examining tourist food consumption systematically, the multidisciplinary approach adopted in this study allows a comprehensive understanding of the phenomenon which forms the basis for further research and conceptual elaboration.
\end{abstract}

Keywords: tourist food consumption; travel eating behaviour; food and gastronomy; food consumption in tourism.

\section{Introduction}

Tourist food consumption, a crucial form of tourist consumption, has largely been neglected in the hospitality and tourism literature (Cohen \& Avieli, 2004). This neglect was due to the traditional notion that food is a 'supporting resource' (Godfrey \& Clarke, 2000) which supplements a destination's appeal to its tourists, and also to the conventional view that eating while travelling is a 'supporting consumer experience' (Quan \& Wang, 2004), one that is largely an extension of tourists' daily routines. However, recent years have witnessed a surge of research interest in food consumption in tourism, covering areas such as food service (Nield, Kozak, \& LeGrys, 2000; Sheldon \& Fox, 1988), local food consumption (Kim, Eves, \& Scarles, 2009; Ryu 
\& Jang, 2006; Torres, 2002), food/gastronomic experiences in tourism (Chang, Kivela, \& Mak, 2011; Kivela \& Crotts, 2006, 2009), and tourist food preferences and choice (e.g., Chang, Kivela, \& Mak, 2010; Torres, 2002). This growing interest is fuelled by an increasing number of destinations utilising their culinary resources in promoting and differentiating themselves from others, for example, Australia, New Zealand, Italy, and Singapore (Chang et al., 2010; Hall \& Mitchell, 2002a; Scarpato, 2002). Despite the recent growing attention, Kim, Eves and Scarles (2009), however, point to the fact that research in the field is in its infancy and its basic tenets is still being established. The need for research on this important aspect of hospitality and tourism has been urged by a number of researchers (Chang et al., 2010; Cohen \& Avieli, 2004; Stewart, Bramble, \& Ziraldo, 2008). Au and Law (2002) contend that tourist food demand tends to be inelastic. Other studies indicate that food consumption expenditure can constitute up to one-third of the total tourist expenditure (Telfer \& Wall, 2000). Hence, the economic benefits brought by tourist food consumption can significantly affect the economic viability and sustainable competitiveness of a destination and the hospitality businesses operating in the locality.

While the economic significance of tourist food consumption is recognised, little research has systematically and comprehensively explored the factors affecting tourist food consumption. This study attempts to address this deficiency by consolidating existing hospitality and tourism literature to identify the salient factors affecting tourist food consumption and the interrelationships among these factors. Taking into consideration the idiosyncratic nature of food consumption in tourism - its essentiality on one hand (Richards, 2002) and its symbolic nature on the other (Chang et al., 2010; Kivela \& Crotts, 2006) - a multidisciplinary approach is adopted in this study. The aim is to synthesise relevant perspectives from hospitality and tourism, food consumption, and sociological research to generate a thorough understanding of the phenomenon. However, due to space constraints, this paper does not address the relationships between food production and consumption in destinations; rather, it is focused on the literature dealing with the socio-cultural and psychological factors affecting tourist food consumption.

\section{Tourist Food Consumption}

Food consumption studies are predominantly concerned with understanding the determinants of various food-related behaviours, most commonly including liking, preference, choice and intake. Although many studies used these terms interchangeably, there are subtle differences between them. Food liking refers to 'the palatability or pleasure obtained from tasting 
a given food' (Giesen et al., 2010, p. 966), whereas food preference 'assumes the availability of at least two different items, and refers to the choice of one rather than the other' (Rozin \& Vollmecke, 1986, p. 434). Although in most cases people prefer foods that they like better, food liking is only one of the motivations that may account for a preference. Factors such as availability, perceived health value, convenience, and economic considerations that can influence food preference may not affect food liking (Logue, 1991).

Food choice refers to 'a set of conscious and unconscious decisions made by a person at the point of purchase, at the point of consumption or any point in between' (Herne, 1995, p. 13). In an aggregate form, food choice creates the consumer demand for suppliers in the food system who produce, process, and distribute food (Sobal, Khan, \& Bisogni, 1998). Food choice also plays an essential role in the symbolic, economic, and social aspects of life as it is a way to express preferences, identities, and cultural meanings (Sobal et al., 2006). Food intake refers to the amount of food actually consumed by an individual (Kissileff \& Van Itallie, 1982). It is usually stated in terms of weight, calories, or volume of mixed quantity of macro- and micro-nutrients in food research.

In summary, food liking, preference, choice and intake refer to overlapping, but not precisely equivalent concepts associated with food consumption behaviour (Logue, 1991). Rozin (2006, p. 24) provides a rather succinct description of their relationship: 'liking is a major determinant of preference, and preference is a major determinant of intake, but many other variables intervene'. To risk oversimplification, their relationship can be summarised as Fig. 1, with 'intervening variables' suggested by Rozin (2006) being depicted as one single variable that exert indirect influences. These 'intervening variables', which can be grouped into three broad categories: the individual, the food, and the environment, are discussed in the subsequent section. Taking into consideration the practical usefulness of food preference over food liking, the social and economical significance of food choice in its aggregate from, and the potential difficulties to measure tourists' food intake during their travel, the primary focus of this study is on tourist food preference and choice. Additionally, this focus also reflects the current state of the field, for existing studies on tourist food consumption largely adopted the preference and choice approach (e.g., Chang et al., 2010; Kim et al., 2009; Torres, 2002).

\section{* please insert Fig. 1 about here}

Food consumption is recognised as a complex behaviour, with cultural, social, psychological, 
and sensory acceptance factors all playing a role in the decision-making process (Köster, 2009; Sobal et al., 2006). Various attempts have been made to address the plethora of factors affecting food consumption (e.g., Booth \& Shepherd, 1988; Eertmans, Baeyens, \& Van den Bergh, 2001; Fotopoulos et al., 2009; Furst et al., 1996; Khan, 1981; Steptoe, Pollard, \& Wardle, 1995). In general, food researchers agree that these factors can be classified into three broad categories: the individual, the food, and the environment (Gains, 1994; Meiselman et al., 1999; Randall \& Sanjur, 1981; Shepherd \& Raats, 1996). The food itself contributes sensory attributes such as flavour, aroma, texture, and appearance; whereas the environment presents cultural, social, economic and physical influences. As for the individual, socio-cultural, psychological, and physiological factors are recognised to exert direct or indirect effects on food consumption behaviour. Amongst these three broad categories, factors relating to 'the individual' are widely accepted to be extremely crucial in explaining the variations in food consumption (Rozin, 2006).

By adapting Randall \& Sanjur's (1981) theoretical model which categorises the factors influencing food preferences into the individual, the food, and the environment, the present study proposes that potential factors affecting food consumption in the context of tourism can likewise be categorised into three main categories: the tourist, the food in the destination, and the destination environment (Fig. 2). Food in the destination presents factors such as sensory attributes, food content, cooking methods (Chang et al., 2010; Cohen \& Avieli, 2004). The destination environment contributes factors such as gastronomic image/identity, marketing communications, service encounter, and servicescape (i.e., physical elements in a consumption setting's built environment) (Chang et al., 2011; Fox, 2007; Harrington, 2005). Arguably, these factors can be more complex than food consumption in home settings, for there is a substantial change in both the 'food' and the 'environment' components. Above all, tourists' former attitude towards food and eating might change, and a different set of motivations might influence their preferences and choice of food in the new and unfamiliar environment. Limited space precludes a full discussion of the wide ranging factors classified under these three categories. Given the focus of this study is on tourist food consumption, the factors pertaining to the tourists are elaborated in the ensuing sections.

\section{* please insert Fig. 2 about here}

\section{Factors Influencing Tourist Food Consumption}

A review of tourism literature reveals that existing studies on tourist food consumption are 
largely related to the areas of food service (Nield et al., 2000; Sheldon \& Fox, 1988), local food consumption (Kim et al., 2009; Ryu \& Jang, 2006; Torres, 2002), food and gastronomic experiences in tourism (Chang et al., 2011; Kivela \& Crotts, 2006, 2009), food as a form of special interest tourism (Hall et al., 2003; Ignatov \& Smith, 2006; Long, 2004), and tourist food preferences and choice (Chang et al., 2010; Torres, 2002). Although there is a lack of attempt at systematically addressing the factors affecting tourist food consumption and their interrelationships, the above studies provide important groundwork for understanding the phenomenon. Based on the findings of these studies, it is evident that a distinct set of factors may influence tourist food consumption behaviour. These potential factors can be classified into the following five main categories: cultural and religious influence, socio-demographic factors, food-related personality traits, exposure and past experience, and motivational factors. Table 1 presents the five factors along with respective authors and related concepts. The ensuring sections elaborate on these factors by drawing evidence from the tourism literature, as well as incorporating theoretical insights from food consumption and sociological research.

\section{* please insert Table 1 about here}

\subsection{Cultural and Religious Influences}

Culture and religion have long been recognised as major determinants affecting general food consumption. Culture can be defined as a shared set of characteristics, attitudes, behaviours, and values that helps groups of people decide what to do and how to go about it (Goodenough, 1971). Culture 'guides' the behaviour of a particular group in all affairs of life and designates the socially standardised activities of people, including the human 'foodways'. Accordingly, culture is a major determinant affecting the types of substances that a person considers appropriate to eat (Atkins \& Bowler, 2001; Logue, 1991). It defines how food is coded into 'acceptable' or 'unacceptable', and 'good' or 'bad' within a particular social group (Mäkelä, 2000). Culture further determines which foods and food qualities are acceptable in terms of their sensory properties (Prescott et al., 2002). This process is manifested in the existence of culturally specific 'flavour principles'. According to Rozin and Rozin (1981), basic foods, cooking techniques, and flavour principles are three major factors that differentiate a cuisine, and flavour principles refer to the distinctive seasoning combinations which characterise many cuisines.

Religious background are also considered as crucial determinants affecting food choice and consumption (Khan, 1981). Religious beliefs have an impact on food consumption when certain 
foods are prohibited (e.g., Islam, Judaism), particular preparation methods are mandated (e.g., halal, kosher), or fasting or feasting practices are observed (e.g., Ramadan) (Packard \& McWilliams, 1993). These practices and restrictions can result in stable and rigid food habits (Khan, 1981) and thus, not just affect food consumption in tourists' home settings, but also in the context of tourism. Using Muslim tourists as an example, Islamic teachings about eating behaviour have classified the food broadly into halal (permissible) and haram (prohibited). It is obligatory for all Muslims to eat only halal food even when they are travelling in foreign destinations (Bon \& Hussain, 2010).

The influences of culture and religion on tourist food consumption have been recognised by a number of hospitality/tourism studies. For example, Pizam and Sussmann (1995) indicate that Japanese, French, and Italian tourists were observed as avoiding local food in the host destination and always preferring to eat their own cuisine; whereas American tourists were perceived to have a slight preference for local food in the host destination. Similarly, March's (1997) study, which involved interviews with various stakeholders in the travel industry, has identified a number of behavioural similarities and differences amongst tourists originated from five Asian outbound markets (Indonesia, Japan, South Korea, Taiwan and Thailand). One of the behavioural differences is food consumption pattern, which was found to be influenced by cultural or religious factors. As March (1997, p. 234) states, 'as Muslims, Indonesians require specially prepared halal food, while Koreans have a strong preference for their own cuisine.' In a study on the role of food service in vacation choice, Sheldon and Fox (1988) found that Japanese tourists tended to be less willing to try new cuisines compared with U.S. and Canadian tourists when holidaying in Hawaii. Torres's (2002) study found discernible differences in food consumption and preferences amongst Yucatan tourists of different nationalities and tourist-types. She found that while there was considerable demand for Mexican food, tropical fruits, and organic foods among all tourists in the sample, demand appeared to be greater amongst non-American and 'off-beat' tourists. Interestingly, many the above studies lend support to Cohen and Avieli's (2004, p. 775) contention that 'Asians abroad tend to be less disposed than Westerners to partake of the food of "others", and are more dependent than the later on establishments providing their own national cuisines.'

Despite the preliminary evidence presented above, relatively little is known about to what extent and in what specific aspects culture and religion have impacted food consumption in tourism. Until recently, a number of tourism studies have shed more light on the topic. For example, Tse and Crotts (2005) propose a link between tourist culinary choice and their national 
culture. Their findings indicate that respondents from low 'uncertainty avoidance index' countries (Hofstede, 2001), that is where people are less risk-averse, patronised a greater number and diversity of culinary offers in Hong Kong compared with respondents from high uncertainty avoidance countries. This presents an interesting proposition that national culture, in particular the risk-aversion domain, can exert significant collective influence on tourist food consumption. On the other hand, Chang et al. (2010) found that tourists' culturally-specific 'core eating behaviour' is a crucial factor affecting their food preferences on holiday. Tourists are generally more willing to accept changes in 'secondary' foods (i.e., foods eaten widely and often, but not daily) and 'peripheral' foods (i.e., foods eaten sporadically) on holiday, yet tend to remain steadfast to 'core' foods (i.e., staples that are consumed almost daily). This supports the core and peripheral foods model in food consumption literature (Kittler \& Sucher, 2004) which suggests that core foods are closely associated with a culture and face the biggest resistance to be changed or modified. Furthermore, Chang et al. (2011) found that tourists' own food culture can exert a great deal of influence on their perceptions and evaluation of foreign food, particularly in terms of flavour and cooking method. The finding highlights the importance of understanding the 'cultural distance' (McKercher \& Chow, 2001) and culturally-specific 'flavour principles' (Rozin \& Rozin, 1981) between tourists' native food culture and the host food culture in affecting tourist food consumption.

As for religious influence, Hassan and Hall (2003) is one of the few attempts in examining how religious beliefs have impacted the food consumption behaviour of Muslim tourists visiting New Zealand. It was found that a vast proportion of the sample $(82.2 \%)$ would always look for halal food when travelling in New Zealand, and a majority of them (39.6\%) stated that they always prepared their own meals due of a lack of knowledge of the availability of halal food in New Zealand. Alternatively, Cohen and Avieli (2004, p. 760) suggest that 'while on tour, many Israelis tend to relax their avoidance of non-kosher food, but remain extremely worried about hygiene and about culturally unacceptable food such as dog, cat, and reptile meat'. This echoes with Rotkovitz's (2004) argument that given the transient nature of tourism, even kosher-observant tourists might take on greater psychological openness to experimentation with new foods or foodways when on holiday.

\subsection{Socio-demographic Factors}

Socio-demographic factors commonly include indicators such as age, gender, marital status, education level, occupation, and household income to reflect the socio-economic and demographic 
status of an individual. While closely related to cultural background, socio-demographic factors allow investigations into socio-economic and demographic variables as within-culture determinants of food consumption. In many food consumption research, socio-demographic factors are recognised to be important variables in explaining variations in food consumption in different contexts (e.g., Furst et al., 1996; Khan, 1981; Randall \& Sanjur, 1981). In particular, evidence suggests that age, gender, and social status (or social class) are significant in accounting for variations in food preferences. For example, Khan (1981) contends that owing to diminished taste and olfactory sensitivity, older people tend to display different food preferences as compared to younger persons. Rozin (2006) points out that meat avoidance, weight concerns, and preference for low-calorie foods are higher in women in USA.

Evidence from the tourism literature suggests that tourist food consumption can be influenced by socio-demographic factors. For instance, Tse and Crotts (2005) found that tourists' age was negatively correlated with the number and range of their culinary explorations. This suggests that elder tourists may consume a narrower range of foods available in a destination. Kim et al. (2009) also identified gender, age, and education as three socio-demographic variables that affect tourists' local food consumption. In particular, female interviewees were found to be more interested in and excited about tasting local food when on holiday. Elder interviewees and interviewees with higher education level were found to be more concerned about health and had a stronger desire to understand and experience foreign cultures through local food consumption. However, using socio-demographic factors to explain variations in tourist food consumption is not totally unproblematic. Khan (1981) points to the interrelationship between certain socio-demographic factors, such as education, occupation, and age. As he contends, people with a higher education level might have a higher social-status occupation and can be older. Notwithstanding this shortcoming, socio-demographic factors provide important ways to examine how socio-economic and demographic variables serve as within-culture determinants of tourist food consumption.

On the other hand, since food also serves as a 'social marker' which identifies one's group (Rozin, 2006), social status is one of the pervasive factors affecting the types and quantity of foods eaten and the perceived meanings of foods. From a sociological perspective, structuralist Barthes (1975) notes that food preferences vary according to social class. In elaborating a 'grammar of foods' (in Barthes' term, food can be interpreted as signs in a system of communication), Barthes (1975) further emphasises the signifying power of food; certain foods can be used to signify 
concepts such as tradition, modernity, masculinity, femininity, superior, and inferior (Wood, 1995). Accordingly, food, to a certain extent, reflects the social status and self-identity of an individual. Post-structuralist Bourdieu (1984) also emphasises that the differences in food preferences are related to social class. For example, middle-class individuals who are rich in 'cultural capital' (in Bourdieu's sense, cultural capital refers to a stock of knowledge and experience people acquire through the course of their lives that enables them to succeed more than someone with less cultural capital) tend to be keen to cultivate 'taste' for exotic and foreign foods to maintain distinctiveness (Bourdieu, 1984). As Heldke (2003) states, this cultivated 'taste' in foreign cuisine can enhance an individual's level of sophistication, which is important for raising stature in future social situations. In this sense, the cultural capital theory is particularly germane in explicating social class differences in food consumption behaviour in tourism. In a recent study, Chang et al. (2010) found that middle-class Chinese tourists considered eating Australian local food would enable them to acquire new food knowledge so that they could have the capacity to discuss and evaluate Australian food. Accordingly, other than socio-economic and demographic status, social class and cultural capital are important concepts in understanding the variations in tourists' food consumption behaviour.

\subsection{Food-related Personality Traits}

Food-related personality traits have begun to be recognised as important psychological variables affecting tourist food consumption. Food-related personality traits refer to individual characteristics that exert a pervasive influence on a broad range of food-related behaviours. In particular, two main types of traits can be identified from the tourism literature: food neophobia and variety-seeking. Food neophobia, or the reluctance to ingest novel foods (Pliner \& Salvy, 2006), is at the heart of the mechanism dictating human food choice. Humans, as omnivorous animals, will try various food sources, however, they will, at the same time, be cautious not to ingest toxic or harmful food sources. Food neophobia, therefore, is described as a "natural biological correlate of omnivorous exploratory behaviour' (Köster \& Mojet, 2007, p. 99). According to Pliner and Salvy (2006), food neophobia can be conceptualised as a personality trait involving a relative preference for familiar over novel foods. This condition is stable over time and consistent across situations. However, there are large individual differences in the extent of food neophobia. Pliner and Hobden (1992) developed the Food Neophobia Scale, a ten-item instrument, to measure individual differences in food neophobia. Research shows that when measured with the scale, people who are more neophobic tend to expect various novel foods to taste worse than the less neophobic, and thus are generally less willing to taste or choose novel 
foods (Pliner \& Hobden, 1992; Tuorila et al., 1998; Tuorila et al., 1994).

Taking a sociological perspective, Fischler (1988) draws a distinction between 'neophobic' and 'neophilic' tendencies in taste, suggesting that a human has a natural tendency to dislike or suspect new and unfamiliar foods (neophobic), and yet, also has a propensity to search for novel foods (neophilic). He further describes the tension between the neophobic and neophilic tendencies as the 'omnivore's paradox', one that constantly occurs in 'the oscillation between the two poles of neophobia (prudence, fear of the unknown, resistance to change) and neophilia (the tendency to explore, the need for change, novelty, variety)' (1988, p. 278). In the tourism literature, the food neophobia concept has been adopted to explain the difference in tourists' food consumption behaviour. For example, Cohen and Avieli (2004) contend that local or indigenous cuisines in a destination can be an 'impediment' instead of an 'attraction' to many tourists. That is, although tourists may typically be eager or willing to engage in 'novel' or 'unusual' experiences (neophilic), eating involves the actual ingestion of unfamiliar food in the destination and thus, neophobic tendency might become more prominent. Likewise, Torres (2002) cites that many studies suggest that tourists in general prefer foods to which they are accustomed and resist trying local varieties. Kim et al. (2009) identified food neophobia and neophilia as two of the factors affecting tourists' inclination to consume local food on holiday. They found that tourists, who have a predisposition to be neophobic, seem to be reluctant to eat exotic food. Chang et al. (2011) suggest that the neophilia concept provides justification for tourists' inclination to seek various dining experiences when on holiday.

Another food-related personality trait that can affect tourist food consumption is variety-seeking. Variety-seeking can be defined as 'the tendency of individuals to seek diversity in their choices of services and goods' (Kahn, 1995, p. 139). The trait can be measured by the 8 -item VARSEEK scale developed by van Trijp and Steenkamp (1992). Variety-seeking tendency has been widely adopted in food consumption studies. For example, Inman (2001) found that consumers tended to switch more intensively between flavour than brand of tortilla chips and cake mixes. The study suggests that consumers are more likely to seek variety on sensory attributes (e.g., flavour) than non-sensory attributes (e.g., brand). The idea of optimum stimulation level provides a basis for understanding variety-seeking behaviour. According to van Trijp (1995), individuals tend to seek additional stimulation by adding variety or novel stimuli when the level of stimulation falls below the optimum. In contrast, they tend to avoid novel stimuli or variety if the level of stimulation is above the optimal point. Therefore, customers tend to veer away from an 
item consumed during the last occasion. By selecting alternatives that have not been chosen recently, individuals may achieve optimum stimulation level, as well as prevent boredom and alleviate attribute satiation (Ratner, Kahn, \& Kahneman, 1999; van Trijp, 1995).

Research indicates that variety-seeking behaviour occurs frequently in the case of hedonic consumption for which diversity among features is a significant consideration (Ratner et al., 1999). Hedonic products can be referred to as products for which fun, pleasure, or enjoyment is a primary benefit, and they tend to generate stronger emotional responses (Carroll \& Ahuvia, 2006). Tourism and gastronomy are often regarded as hedonic products, and thus, can be subject to the influence of variety-seeking behaviour. For instance, Kemperman et al. (2000) found that theme park choice is partly influenced by variety-seeking tendency. Quan and Wang (2004) suggest that variety-seeking behaviour can significantly affect food consumption in tourism. Chang et al.'s (2011) study reveals that variety is one of the key attributes affecting tourist evaluation of their food experience.

\subsection{Exposure Effect/Past Experience}

Based on the food neophobia concept, people generally prefer foods that they are familiar with. The mere exposure effect offers corroboration for this contention. The mere exposure effect refers to a 'positive repetition-affect relationship that results from exposure alone' (Obermiller, 1985 , p. 18). In other words, its essence is reflected by the old aphorism 'familiarity breeds content'. Food consumption literature acknowledges that exposure to certain foods tends to increase preference for those foods, as familiarity increases with repeated exposure (Birch et al., 1987; Luckow et al., 2006; Pliner, 1982; Stein et al., 2003). Past experience with a food also can significantly affect food consumption behaviour. Barker (1982) found that an individual's past experience with a food contribute to the development of 'food memories' which are associated with the sensory attributes of the food. The exposure effect and past experience are found to be important factors affecting tourist food consumption. Tourists' exposure to the local cuisine of a destination, acquired through previous visitation, can increase the familiarity of that cuisine and thus potentially enhance their preference towards it. The study conducted by Tse and Crotts (2005) supports this, indicating that repeat visitation was found to be positively correlated with both the number and range of tourists' culinary explorations, whereas first-time visitation was negatively correlated. Likewise, Ryu and Jang (2006) found that past experience is one of the significant predictors of tourists' intention to consume local cuisine in destinations. 
Other than past experience obtained from previous visitation, tourists may have increased exposure to different foreign cuisines under heightened globalisation. Given the growing influence of globalisation, not only have tourists become more mobile, the food they eat has also become more international (Hall \& Mitchell, 2002b; Richards, 2002). There is an increasing availability of both ethnic restaurants in tourists' home settings and information sources about foreign cuisines (Cohen \& Avieli, 2004), which provide tourists with the opportunity to become acquainted with a variety of foreign cuisines before they travel to the destination where these foreign cuisines originated. This might lead to changes in their travel food consumption behaviour. Although one might argue that foreign cuisines in home settings can be very different from those in the originating country, increased exposure and familiarity to foreign cuisine could at least be provided. Increased exposure and familiarity would not only affect the consumption of foreign cuisine in their home settings, but would also affect the consumption of the foreign cuisine when they travel. Chang et al. (2010) observed disparities in food consumption behaviour amongst Hong Kong, Taiwanese and Mainland Chinese tourists with varying degrees of exposure to Western cuisines in their home settings. Furthermore, tourists' varying levels of exposure were found to be associated with different motivational factors and attitudes towards food consumption in tourism.

\subsection{Motivational Factors}

A growing body of studies have demonstrated that motivational factors can significantly affect tourist food consumption. First of all, a number of studies explore how food per se can be the major, or one of the major, motivations to travel to a destination (Hall \& Mitchell, 2001; Hjalager \& Richards, 2002; Long, 2004). Kivela and Crotts (2006) contend that motivation to travel for food/gastronomy is a valid construct, and that food plays an important role in affecting the overall tourist experience and intention to revisit a destination. Ignatov and Smith (2006) found that travel motivations and activities differed significantly among different Canadian culinary tourist segments. Furthermore, Fields (2002) adopts the typology of tourist motivators suggested by McIntosh, Goeldner, and Ritchie (1995) to elaborate on the interplay between food consumption and tourism. The four motivators are: physical, cultural, interpersonal, and status and prestige motivators. First, food can be a physical motivator as the act of eating is predominately physical in nature involving sensory perceptions to appreciate the food or tourists' need for 
sustenance. Second, food can also be a cultural motivator because when tourists are experiencing new local cuisines, they are simultaneously experiencing a new culture. Third, it might serve as an interpersonal motivator as meals taken on a holiday have a social function including building new social relations and strengthening social bonds. Finally, local delicacies can also be a status and prestige motivator, as tourists can build their knowledge of the local cuisine by eating as the locals do, and exploring new cuisines and food that they or their friends are not likely to encounter at home.

While the proposition of Fields (2002) lacks empirical evidence, it suggests a theoretical linkage between tourist motivation and motivational factors underlying food consumption in tourism. Tourist motivation is recognised as an important construct in understanding tourist choice and behaviour (Crompton \& McKay, 1997). It can be defined as the 'global integrating network of biological and cultural forces which gives value and direction to travel choices, behaviour, and experience' (Pearce, Morrison, \& Rutledge, 1998, p. 215). Tourist motivation embraces psychological as well as physiological facets because travel is expected to satisfy different levels of needs such as psychological (e.g., intrinsic, personal, and interpersonal rewards) and physiological needs (e.g., food, shelter, safety, health, and fitness) (Mak, Wong, \& Chang, 2009; Witt \& Wright, 1992). Since tourist motivation exerts significant influence over tourist choice and behaviour, it can be a significant force affecting tourist food consumption. For example, a tourist motivated to visit a destination by its cultural factors may be more inclined to try local traditional food in order to explore the local food culture.

Following on Fields' (2002) proposition, motivations underlying food consumption can be regarded as multi-dimensional. Some recent studies provide additional empirical evidence to substantiate this contention. For example, based on a series of qualitative interviews, Kim et al. (2009) identified nine motivational factors underlying the consumption of local food: exciting experience, escape from routine, health concern, learning knowledge, authentic experience, togetherness, prestige, sensory appeal, and physical environment. Drawing on data from a series of on-site focus group interviews and participant observation with Chinese tourists holidaying in Australia, Chang et al. (2010) classified Chinese tourists' food preferences into three distinct categories: Chinese food, local food, and non-fastidious about food selection. The underlying motivational factors for favouring each preference were identified as: (1) Chinese food: core eating behaviour, familiar flavour, and appetizing assurance; (2) local Australian food: explore local culture, authentic travel experience, learning/education opportunity, prestige and status, 
reference group influence, and subjective perception; (3) non-fastidious about food selection: group harmony, compromising in supporting experience, and prejudiced advocacy.

Based on the above findings, motivational factors underlying tourist food consumption can be conceptually classified into five key dimensions: symbolic, obligatory, contrast, extension, and pleasure. The symbolic dimension refers to the motivators that signify the symbolic meanings of food consumption to the tourists, and includes factors such as explore local culture, authentic experience, learning/education, prestige and status (Mak, Lumbers, \& Eves, 2011). The obligatory dimension reflects the essentiality of food consumption in tourism, and includes factors such as health concern, and the physical need for sustenance. The contrast dimension denotes the motivation to seek contrast from the tourists' daily routine experience (Quan \& Wang, 2004), and includes factors such as exciting experience and exploring new food. In contrast, the extension dimension refers to the motivations to seek food experiences that extend the tourists' daily routine, and includes factors such as core eating behaviour, and familiar flavour. Finally, the pleasure dimension covers the motivations to seek pleasure from the food experience, and includes factors such as sensory appeal and togetherness.

The classification is based on the following theoretical underpinnings. From the tourist product perspective, food in tourism can be seen as an 'attraction' (Hjalager \& Richards, 2002), and yet, can also be viewed as an 'impediment' which discourages tourists from visiting a destination (Cohen \& Avieli, 2004). This schism is principally based on different emphases on the 'symbolic' and 'obligatory' dimensions of food consumption in tourism. Generally, food consumption in tourism is recognised as a 'symbolic' form of consumption (Mak et al., 2011). Certain 'cultural' theories pertaining to food consumption and dining out in the general context are adopted to explicate the 'symbolic' nature of food consumption in tourism, for example, the cultural capital theory discussed above. On the other hand, food consumption in tourism also possesses an 'obligatory' nature (Richards, 2002). As Quan and Wang (2004, p. 302) put it, 'a large portion of food consumption in tourism can be seen as the supporting experience for tourists to complete or realize their main purpose of travel'. From the tourist experience perspective, food consumption in tourism can be conceptually distinguished into 'supporting consumer experience' and 'peak touristic experience' (Quan \& Wang, 2004). This distinction is based on food consumption's relationship to tourists' daily routine, whether it is contrasting, intensifying, or merely extending the daily routine experience. In other words, this approach accentuates the importance of the 'contrast' and 'extension' dimensions in interpreting food consumption in 
tourism. Lastly, tourism and gastronomy are often regarded as hedonic products (Kemperman et al., 2000; Kivela \& Crotts, 2006), for which fun, pleasure, or enjoyment is a primary benefit (Carroll \& Ahuvia, 2006). Hence, the 'pleasure' dimension can be an inherent dimension in food consumption in tourism.

\section{Conclusion}

This study has consolidated the relevant perspectives on tourism, food consumption, and sociological research to identify the salient factors affecting tourist food consumption. The findings open up many new possibilities for research into food consumption in tourism. By drawing on Randall and Sanjur's (1981) food preference model, this study posits that factors affecting food consumption in the context of tourism can be classified into three key areas concerning the tourist, the food in the destination, and the destination environment (Fig. 2). Although the factors listed under each area may not be exhaustive, it provides a clear and cogent framework for further investigation into the factors pertaining to the food and the destination environment.

In addition, by reviewing available research evidence in the hospitality/tourism literature and synthesising insights from food consumption and sociological research, this study identified five major socio-cultural and psychological factors influencing tourist food consumption: cultural/religious influences, socio-demographic factors, food-related personality traits, exposure effect/past experience, and motivational factors. It is posited that the five factors are potentially interrelated. For example, cultural/religious influences may have varying degrees of influence on socio-demographic factors. Similarly, food-related personality traits may affect exposure and past experience, and the influence can be reciprocal. Tourists with different cultural/religious backgrounds and socio-demographic characteristics, and with varying food-related personality traits and exposure and past experience may have different motivations towards food consumption in tourism. Furthermore, the findings support existing evidence that motivational factors are important variables influencing tourist food preference. By analysing the findings of previous studies, this study proposes that the motivational factors can be theoretically categorised into five main dimensions: symbolic, obligatory, contrast, extension, and pleasure. This classification of the dimensions affords a generalisable framework (Fig. 3) for future investigation into the motivational factors underlying tourist food consumption in different settings, making comparison of results possible. 
* please insert Fig. 3 about here

Despite the contributions of the findings, a number of limitations in this study should be noted. First, given that food consumption behaviour is affected by a wide range of interacting factors (Köster, 2009), the proposed framework therefore does not incorporate all possible factors that affect tourist food consumption. For example, physiological effects such as hunger and satiety (Shepherd, 1985) are not included in the framework (Fig. 3), but are included in the broader model which summarised the wide ranging factors affecting food consumption in tourism (Fig. 2). Rather, the focus of the framework is on the socio-cultural and psychological factors that influence the food consumption behaviour of tourists instead of being destination-specific or cuisine-specific. Hence, the framework's generalisability is enhanced and can be adopted as a framework for studies in various settings. Second, attitude is not included in the model due to the belief that attitude accounts for considerably less of the variance in more 'global dietary behaviours' than 'specific dietary behaviours' (Conner \& Armitage, 2006). In other words, attitude might have better explanatory power for consuming a particular type of food (e.g., different types of fruits or organic food) than for consuming a variety of food in more complex situations (e.g., various food items/cuisines in a destination). In addition, Sherman and Fazio (1983) point out many parallels between attitudes and personality. Hence, to a certain extent, food-related personality traits (in particular food neophobia) can reflect tourists' attitude towards novel and familiar food items. Finally, given the theoretical nature of the model, further research is required to determine its utility and validity.

Understanding tourists' needs and wants in terms of food consumption is of paramount importance to hospitality businesses (Santich, 2007). An in-depth knowledge pertaining to factors influencing tourist food consumption is, therefore, extremely valuable to the hospitality sector in providing the appropriate tourism dining experiences that can lead to tourist satisfaction. This value extends as well to the tourism sector in developing and promoting gastronomic products and associated events or activities. Given the current lack of studies focusing on examining tourist food consumption systematically and holistically, the framework developed through a multidisciplinary approach in this study is believed to contribute to the body of knowledge in the field and provides theoretical groundwork for further research. 


\section{References}

Atkins, P., \& Bowler, I. (2001). Food in Society. London: Arnold.

Au, N., \& Law, R. (2002). Categorical classification of tourism dining. Annals of Tourism Research, 29(3), 819-833.

Barthes, R. (1975). Towards a psychology of contemporary food consumption. In E. Forster \& R. Forster (Eds.), European Diet form Pre-industrial to Modern Times. New York: Harper \& Row.

Birch, L. L., McPhee, L., Shoba, B. C., Pirok, E., \& Steinberg, L. (1987). What Kind of Exposure Reduces Children's Food Neophobia. Appetite, 9, 171-178.

Bon, M., \& Hussain, M. (2010). Halah Food and Tourism: Prospects and Challenges. In N. Scott \& J. Jafari (Eds.), Tourism in the Muslim World: Bridging Tourism Theory and Practice (Vol. 2, pp. 47-59). Bingley: Emerald Group Publishing.

Booth, D. A., \& Shepherd, R. (1988). Sensory influences on food acceptance: the neglected approach to nutrition promotion. British Nutrition Foundation Nutrition Bulletin, 13(39-54).

Bourdieu, P. (1984). Distinction: A Social Critique of the Judgement of Taste. Cambridge, MA: Harvard University Press.

Carroll, B. A., \& Ahuvia, A. C. (2006). Some antecedents and outcomes of brand love. Marketing Letter, 17, 79-89.

Chang, R. C. Y., Kivela, J., \& Mak, A. H. N. (2010). Food preferences of Chinese tourists. Annals of Tourism Research, 37(4), 989-1011.

Chang, R. C. Y., Kivela, J., \& Mak, A. H. N. (2011). Attributes that Influence the Evaluation of Travel Dining Experience: When East meets West. Tourism Management, 32(2), 307-316.

Cohen, E., \& Avieli, N. (2004). Food in Tourism: Attraction and Impediment. Annals of Tourism Research, 31(4), 755-778.

Conner, M., \& Armitage, C. J. (2006). Social Psychological Models of Food Choice. In R. Shepherd \& M. Raats (Eds.), The Psychology of Food Choice (pp. 41-57). Oxfordshire: CABI.

Crompton, J. L., \& McKay, S. L. (1997). Motives of visitors attending festival events. Annals of Tourism Research, 24(2), 425-439.

Eertmans, A., Baeyens, F., \& Van den Bergh, O. (2001). Food likes and their relative importance in human eating behaviour: review and preliminary suggestions for health promotion. Health Education Research, 16(4), 443-456.

Fields, K. (2002). Demand for the Gastronomy Tourism Product: Motivational Factors. In A. M. Hjalager \& G. Richards (Eds.), Tourism and Gastronomy (pp. 37-50). London: Routledge.

Fischler, C. (1988). Food, Self and Identity. Social Science Information, 27, 275-292.

Fotopoulos, C., Krystallis, A., Vassallo, M., \& Pagiaslis, A. (2009). Food Choice Questionnaire (FCQ) revisited. Suggestions for the development of an enhanced general food motivation model. Appetite, 52(1), 199-208.

Fox, R. (2007). Reinventing the gastronomic identity of Croatian tourist destinations. International Journal of Hospitality Management, 26, 546-559.

Furst, T., Connors, M., Bisogni, C. A., Sobal, J., \& Falk, L. W. (1996). Food choice: A conceptual model of 
the process. Appetite, 26, 247-266.

Gains, N. (1994). The repertory grid approach. In H. J. H. MacFie \& D. M. H. Thomson (Eds.), Measurement of Food Preferences (pp. 51-76). London: Blackie Academic and Professional.

Giesen, J. C. A. H., Havermans, R. C., Douven, A., Tekelenburg, M., \& Jansen, A. (2010). Will Work for Snack Food: The Association of BMI and Snack Reinforcement. Obesity, 18(5), 966-970.

Godfrey, K., \& Clarke, J. (2000). The tourism development handbook. London: Cassell.

Goodenough, W. H. (1971). Culture, Language, and Society. Addison-Wesley, Reading, MA: Modular Publication.

Hall, C. M., \& Mitchell, R. (2001). Wine and Food Tourism. In N. Douglas \& R. Derrett (Eds.), Special Interest Tourism: context and cases (pp. 307-329). Brisbane: John Wiley.

Hall, C. M., Sharples, L., Mitchell, R., Macionis, N., \& Cambourne, B. (Eds.). (2003). Food Tourism Around the World: development, management and markets. Oxford: Butterworth-Heinemann.

Hall, M., \& Mitchell, R. (2002a). The Changing Nature of the Relationship Between Cuisine and Tourism in Australia and New Zealand: from Fusion Cuisine to Food Networks. In A. M. Hjalager \& G. Richards (Eds.), Tourism and Gastronomy (pp. 187-206). London: Routledge.

Hall, M., \& Mitchell, R. (2002b). Tourism as a force for gastronomic globalization and localization. In A. M. Hjalager \& G. Richards (Eds.), Tourism and Gastronomy (pp. 71-90). London: Routledge.

Harrington, R. J. (2005). Defining gastronomic identity: The impact of environment and culture on prevailing components, texture and flavors in wine and food. Journal of Culinary Science and Technology, 4(2-3), 129-152.

Hassan, M. W., \& Hall, C. M. (2003). The demand for halal food among Muslim travellers in New Zealand. In C. M. Hall, Sharples, L., Mitchell, R., Macionis N. and Cambourne, B. (Ed.), Food Tourism Around the World: Development, management and markets (pp. 81-101). Oxford: Butterworth Heinemann.

Heldke, L. (2003). Exotic Appetites: Ruminations of a food adventurer. New York: Routledge.

Herne, S. (1995). Research on food choice and nutritional status in elderly people: a review. British Food Journal, 97(9), 12-29.

Hjalager, A. M., \& Richards, G. (Eds.). (2002). Tourism and Gastronomy. London: Routledge.

Hofstede, G. (2001). Cultures consequences: Comparing values, behaviors, institutions, and organizations across nations (2nd ed.). Thousand Oaks: Sage.

Ignatov, E., \& Smith, S. (2006). Segmenting Canadian Culinary Tourists. Current Issues in Tourism, 9(3), 235-255.

Inman, J. J. (2001). The Role of Sensory-Specific Satiety in Attribute-Level Variety Seeking. Journal of Consumer Research, 28(1), 105-120.

Köster, E. P. (2009). Diversity in the determinants of food choice: A psychological perspective. Food Quality and Preference, 20, 70-82.

Köster, E. P., \& Mojet, J. (2007). Boredom and the reasons why some new products fail. In H. J. H. MacFie (Ed.), Consumer-led food product development (pp. 262-280). Abbington, Cambridge: Wooodhead Publishing. 
Kahn, B. E. (1995). Consumer variety-seeking among goods and services. Journal of Retailing and Consumer Services, 2, 139-148.

Kemperman, A. D. A. M., Borgers, A. W. J., Oppewal, H., \& Timmermans, H. J. P. (2000). Consumer Choice of Theme Parks: A Conjoint Choice Model of Seasonality Effects and Variety Seeking Behavior. Leisure Sciences, 22, 1-18.

Khan, M. A. (1981). Evaluation of food selection patterns and preferences. CRC Critical Reviews in Food Science and Nutrition, 15, 129-153.

Kim, Y. G., Eves, A., \& Scarles, C. (2009). Building a Model of Local Food Consumption on Trips and Holidays: A Grounded Theory Approach. International Journal of Hospitality Management, 28, 423-431.

Kissileff, H. R., \& Van Itallie, T. B. (1982). Physiology of the Control of Food Intake. Annual Review of Nutrition, 2(1), 371-418.

Kittler, P. G., \& Sucher, K. P. (2004). Accent on Taste: An Applied Approach to Multicultural Competency. Diabetes Spectrum, 17(4), 200-204.

Kivela, J., \& Crotts, J. C. (2006). Tourism and Gastronomy: Gastronomy's Influence on How Tourists Experience a Destination. Journal of Hospitality and Tourism Research, 30(3), 354-377.

Kivela, J., \& Crotts, J. C. (2009). Understanding Travelers' Experiences of Gastronomy Through Etymology and Narration. Journal of Hospitality and Tourism Research, 33(2), 161-192.

Logue, A. W. (1991). The psychology of eating and drinking: an introduction (2nd ed.). New York: WH Freeman.

Long, L. M. (2004). Culinary Tourism. Kentucky: The University Press of Kentucky.

Luckow, T., Sheehan, V., Fitzgerald, G., \& Delahunty, C. (2006). Exposure, health information and flavour-masking strategies for improving the sensory quality of probiotic juice. Appetite, 47, 315-323.

Mäkelä, J. (2000). Cultural Definitions of the Meal. In H. L. Meiselman (Ed.), Dimensions of the Meal: The Science, Culture, Business, and Art of Eating (pp. 7-18). Gaithersburg, M.L.: Aspen Publication.

Mak, A. H. N., Lumbers, M., \& Eves, A. (2011). Globalization and Food Consumption in Tourism. Annals of Tourism Research, (in press).

Mak, A. H. N., Wong, K. K. F., \& Chang, R. C. Y. (2009). Health or Self-indulgence? The Motivations and Characteristics of Spa-goers. International Journal of Tourism Research, 11(2), 185-199.

March, R. (1997). Diversity in Asian outbound travel industries: a comparison between Indonesia, Thailand, Taiwan, South Korea and Japan. International Journal of Hospitality Management, 16(2), 231-238.

McIntosh, R. W., Goeldner, C. R., \& Ritchie, J. R. (1995). Tourism: Principles, Practices, Philosophies. Chichester: John Wiley.

McKercher, B., \& Chow, S. M. B. (2001). Cultural Distance and Participation in Cultural Tourism. Pacific Tourism Review, 5(1), 23-32.

Meiselman, H. L., Mastroianni, G., Buller, M., \& Edwards, J. (1999). Longitudinal measurement of three eating behavior scales during a period of change. Food Quality and Preference, 10, 1-8.

Nield, K., Kozak, M., \& LeGrys, G. (2000). The role of food service in tourist satisfaction. International 
Journal of Hospitality Management, 19, 375-384.

Obermiller, C. (1985). Varieties of mere exposure: the effects of processing style and repetition on affective response. Journal of Consumer Research, 12(June), 17-30.

Packard, D. P., \& McWilliams, M. (1993). Cultural Foods Heritage of Middle Eastern Immigrants. Nutrition Today, 28(3), 6-12.

Pearce, P., Morrison, A. M., \& Rutledge, J. L. (1998). Tourism: Bridges across Continents. Sydney: McGraw-Hill.

Pizam, A., \& Sussmann, S. (1995). Does Nationality Affect Tourist Behavior? Annals of Tourism Research, 22(4), 901-917.

Pliner, P. (1982). The Effects of Mere Exposure on Liking for Edible Substances. Appetite, 2, 283-290.

Pliner, P., \& Hobden, K. (1992). Development of a scale to measure the trait of food neophobia in humans. Appetite, 19(2), 105-120.

Pliner, P., \& Salvy, S. J. (2006). Food Neophobia in Humans. In R. Shepherd \& M. Raats (Eds.), The Psychology of Food Choice. (pp. 75-92). Oxfordshire: CABI.

Prescott, J., Young, O., O'Neill, L., Yau, N. J. N., \& Stevens, R. (2002). Motives for food choice: a comparison of consumers from Japan, Taiwan, Malaysia and New Zealand. Food Quality and Preference, 13, 489-495.

Quan, S., \& Wang, N. (2004). Towards a Structural Model of the Tourist Experience: An Illustration from Food Experience in Tourism. Tourism Management, 25(3), 297-305.

Randall, E., \& Sanjur, D. (1981). Food preferences: their conceptualisation and relationship to consumption. Ecology of Food and Nutrition, 11(3), 151-161.

Ratner, R. K., Kahn, B. E., \& Kahneman, D. (1999). Choosing less-preferred experiences for the sake of variety. Journal of Consumer Research, 26(1), 1-15.

Richards, G. (2002). Gastronomy: An Essential Ingredient in Tourism Production and Consumption? In A. M. Hjalager \& G. Richards (Eds.), Tourism and Gastronomy (pp. 3-20). London: Routledge.

Rotkovitz, M. (2004). Koshering the Melting Pot: Oreos, Sushi Restaurants, "Kosher Treif," and the Observant American Jew. In L. Long (Ed.), Culinary Tourism (pp. 157-185). Lexington: The University Press of Kentucky.

Rozin, E., \& Rozin, P. (1981). Culinary themes and variations. Natural History, 90, 6-14.

Rozin, P. (2006). The Integration of Biological, Social, Cultural and Psychological Influences on Food Choice. In R. Shepherd \& M. Raats (Eds.), The Psychology of Food Choice (pp. 19-39). Oxfordshire: CAB International.

Rozin, P., \& Vollmecke, T. A. (1986). Food Likes and Dislikes. Annual Review of Nutrition, 6, 433-456.

Ryu, K., \& Jang, S. (2006). Intention to experience local cuisine in a travel destination: the modified theory of reasoned action. Journal of Hospitality and Tourism Research, 30(4), 507-516.

Santich, B. (2007). Hospitality and Gastronomy: Natural Allies. In C. Lashley, P. Lynch \& A. Morrison (Eds.), Hospitality: A Social Lens (pp. pp.47-59). London: Elsevier.

Scarpato, R. (2002). Sustainable gastronomy as a tourist product. In A. M. Hjalager \& G. Richards (Eds.), Tourism and Gastronomy (pp. 132-152). London: Routledge. 
Sheldon, P., \& Fox, M. (1988). The Role of Foodservice in Vacation Choice and Experience: A Cross-Cultural Analysis. Journal of Travel Research, 27(3), 9-15.

Shepherd, R. (1985). Dietary Salt Intake. Nutrition and Food Science, 85(5), 10-11.

Shepherd, R., \& Raats, M. (1996). Attitudes and beliefs in food habits. In H. L. Meiselman \& H. J. H. MacFie (Eds.), Food choice, acceptance and consumption. London: Chapman and Hall.

Sobal, J., Bisogni, C. A., Devine, C. M., \& Jastran, M. (2006). A Conceptual Model of the Food Choice Process over the Life Course. In R. Shepherd \& M. Raats (Eds.), The Psychology of Food Choice (pp. 1-18). Oxfordshire: CAB International.

Sobal, J., Khan, L. K., \& Bisogni, C. A. (1998). A conceptual model of the food and nutrition system. Social Science and Medicine, 47, 853-863.

Stein, L. J., Nagai, H., Nakagawa, M., \& Beauchamp, G. K. (2003). Effects of repeated exposure and health-related information on hedonic evaluation and acceptance of a bitter beverage. Appetite, 40, 119-129.

Steptoe, A., Pollard, T. M., \& Wardle, J. (1995). Development of the motives underlying the selection of food: the food choice questionnaire. Appetite, 25, 267-284.

Stewart, J. W., Bramble, L., \& Ziraldo, D. (2008). Key challenges in wine and culinary tourism with practical recommendations. International Journal of Contemporary Hospitality Management, 20(3), 302-312.

Telfer, D. J., \& Wall, G. (2000). Strengthening backward economic linkages: local food purchasing by three Indonesian hotels. Tourism Geographies, 2(4), 421-447.

Torres, R. (2002). Toward a better understanding of tourism and agriculture linkages in the Yucatan: tourist food consumption and preferences. Tourism Geographies, 4(3), 282-306.

Tse, P., \& Crotts, J. C. (2005). Antecedents of novelty seeking: international visitors' propensity to experiment across Hong Kong's culinary traditions. Tourism Management, 26, 965-968.

Tuorila, H., Andersson, A., Martikainen, A., \& Salovaara, H. (1998). Effects of product formula, information and consumer characteristics on the acceptance of a new snack food. Food Quality and Preference, 9, 313-320.

Tuorila, H., Meiselman, H. L., Bell, R., Cardello, A. V., \& Johnson, W. (1994). Role of sensory and cognitive information in the enhancement of certainty and liking for novel and familiar foods. Appetite, 23, 231-246.

van Trijp, H. (1995). Variety-seeking in product choice behavior: Theory with applications in the food domain. The Netherlands: Wageningen.

van Trijp, H. C. M., \& Steenkamp, J.-B. E. M. (1992). Consumers' variety seeking tendency with respect to foods: Measurement and managerial implications. Eur Rev Agric Econ, 19(2), 181-195.

Witt, C. A., \& Wright, P. L. (1992). Tourist motivation: life after Maslow. In P. Johnson \& B. Thomas (Eds.), Choice and Demand in Tourism (pp. 33-55). London: Mansell.

Wood, R. C. (1995). The Sociology of the Meal. Edinburgh: Edinburgh University Press. 


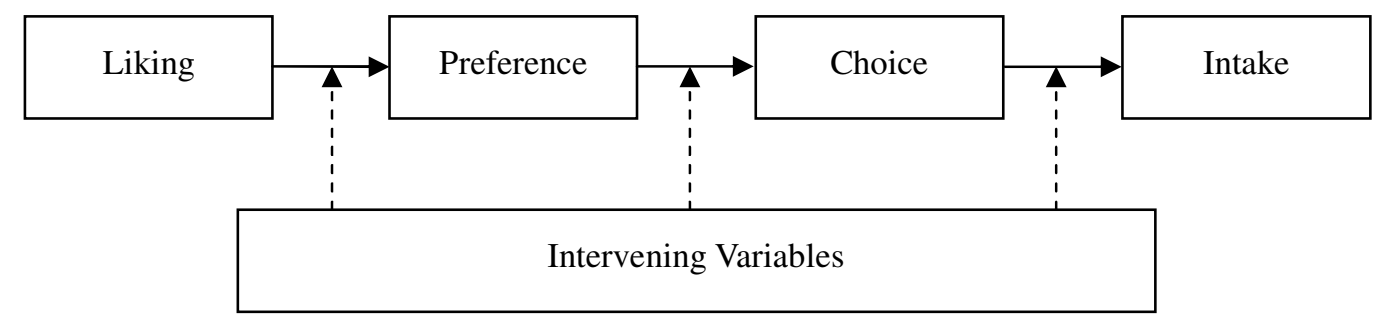

Fig. 1. A schematic representation of the relationship between food liking, preference, choice and intake 


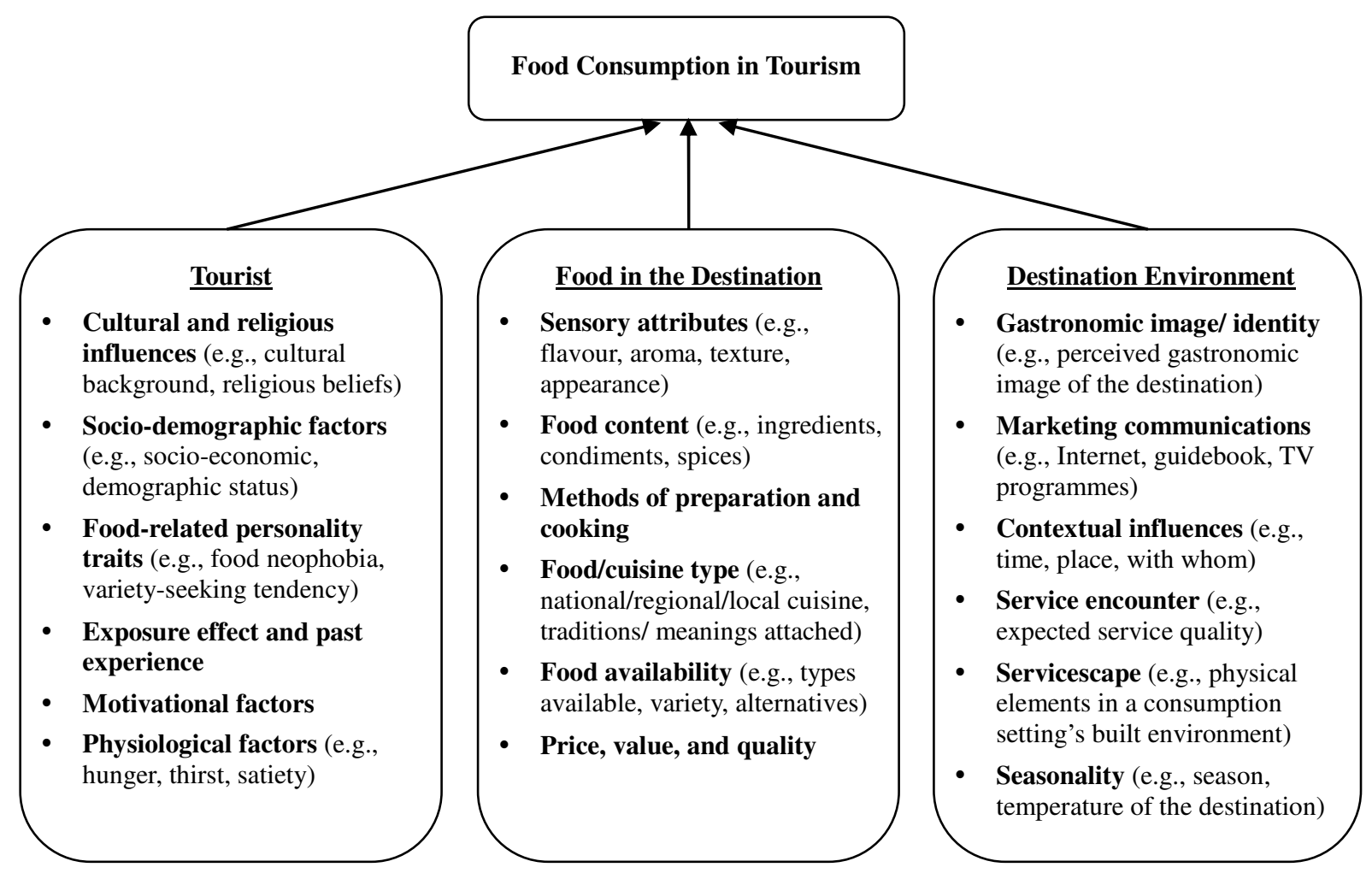

Fig. 2. Factors Affecting Food Consumption in Tourism (adapted from

'A Theoretical Model for the Study of Food Preferences', Randall \& Sanjur, 1981) 
Table 1. Factors, Key Authors and Related Concepts of Tourist Food Consumption

\begin{tabular}{|c|c|c|}
\hline Factors & Key Hospitality/Tourism Authors & Related Concepts \\
\hline Cultural and religious influences & $\begin{array}{l}\text { Sheldon \& Fox, } 1988 \\
\text { Pizam \& Sussmann, } 1995 \\
\text { March, } 1997 \\
\text { Nield et al., } 2000 \\
\text { Torres, 2002 } \\
\text { Hassan \& Hall, } 2003 \\
\text { Tse \& Crotts, } 2005 \\
\text { Chang et al., } 2011\end{array}$ & $\begin{array}{ll}\text { - } & \text { Culture } \\
\text { - National culture } \\
\text { - } & \text { Tourist's own food culture } \\
\text { - } & \text { Cultural distance } \\
\text { - } & \text { Flavour principles } \\
\text { - } & \text { Core and peripheral foods } \\
\text { - } & \text { Religious beliefs }\end{array}$ \\
\hline Socio-demographic factors & $\begin{array}{l}\text { Sheldon \& Fox, } 1988 \\
\text { Pizam \& Sussmann, } 1995 \\
\text { Torres, 2002 } \\
\text { Hassan \& Hall, } 2003 \\
\text { Tse \& Crotts, } 2005 \\
\text { Chang et al., } 2011\end{array}$ & $\begin{array}{l}\text { - Socio-economic status } \\
\text { - Demographic status } \\
\text { - } \text { Social class } \\
\text { - Food as social marker } \\
\text { - } \text { Cultural capital }\end{array}$ \\
\hline Food-related personality traits & $\begin{array}{l}\text { Cohen \& Avieli, } 2004 \\
\text { Kim et al., } 2009 \\
\text { Quan and Wang, } 2004 \\
\text { Chang et al., 2011 }\end{array}$ & $\begin{array}{ll}\text { - } & \text { Food neophobia } \\
\text { - } & \text { Food neophilia } \\
\text { - } & \text { Variety-seeking }\end{array}$ \\
\hline Exposure effect and past experience & $\begin{array}{l}\text { Hall\& Mitchell, 2002b } \\
\text { Richards, 2002 } \\
\text { Cohen \& Avieli, } 2004 \\
\text { Tse \& Crotts, 2005 } \\
\text { Ryu and Jang, } 2006 \\
\text { Chang et al., } 2010\end{array}$ & $\begin{array}{ll}\text { - } & \text { Mere exposure effect } \\
\text { - } & \text { Past experience } \\
\text { - } & \text { Past visitation } \\
\text { - } & \text { Globalisation }\end{array}$ \\
\hline Motivational factors & $\begin{array}{l}\text { Hall \& Mitchell, } 2001 \\
\text { Hjalager \& Richards, } 2002 \\
\text { Fields, } 2002 \\
\text { Long, 2004 } \\
\text { Ignatov \& Smith, } 2006 \\
\text { Kivela \& Crotts, } 2006 \\
\text { Kim et al., 2009 } \\
\text { Kivela \& Crotts, } 2009 \\
\text { Chang et al., } 2010\end{array}$ & $\begin{array}{l}\text { - } \text { Tourist motivation } \\
\text { - Symbolic } \\
\text { - Obligatory } \\
\text { - } \text { Contrast } \\
\text { - Extension } \\
\text { - Pleasure }\end{array}$ \\
\hline
\end{tabular}




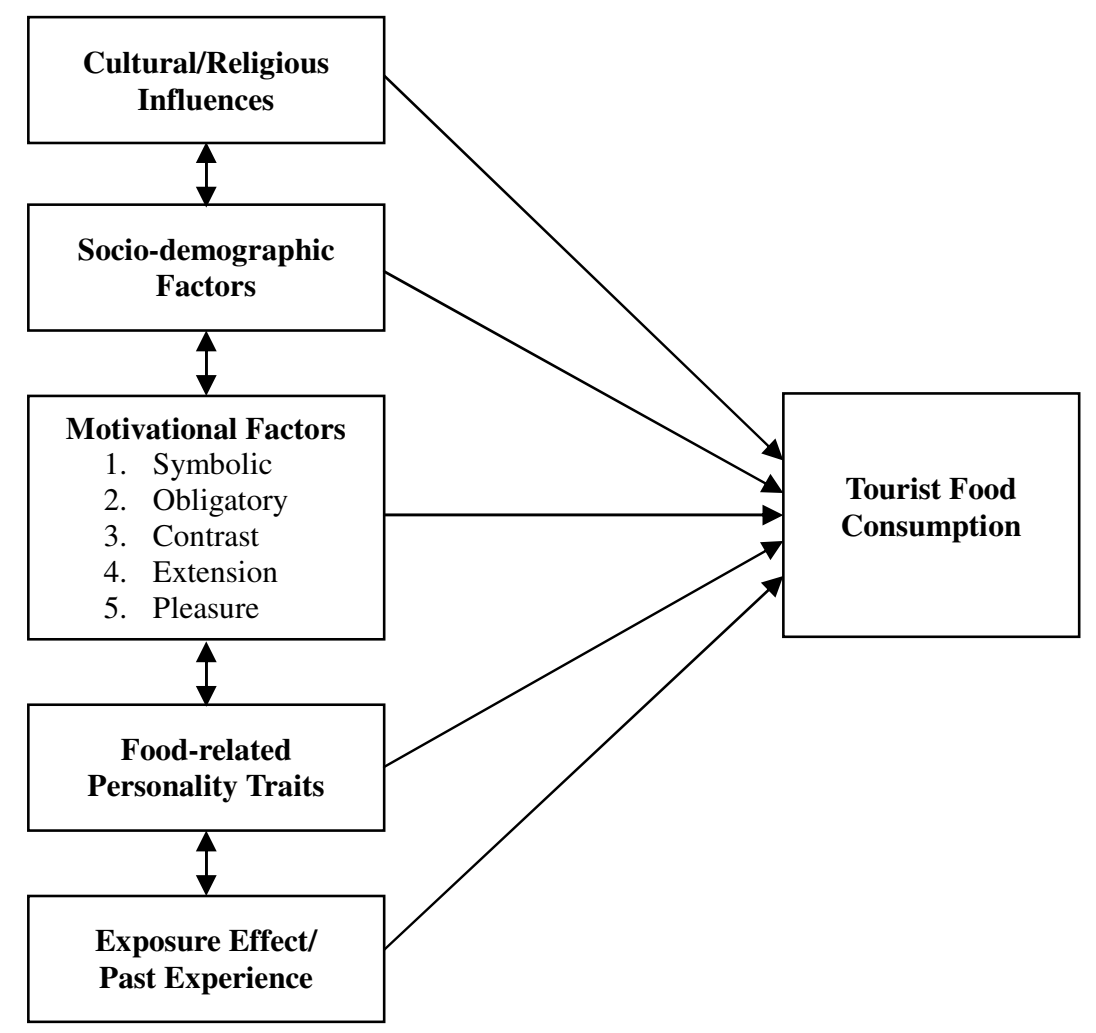

Fig. 3. Factors Influencing Tourist Food Consumption 